\title{
Morphology dominated rapid oxidation of framboidal pyrite
}

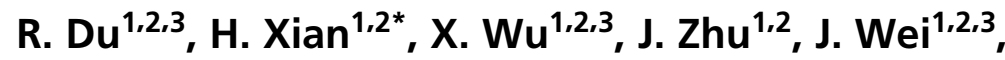 \\ J. Xing ${ }^{1,2,3}$, W. Tan ${ }^{1,2}, \mathrm{H} . \mathrm{He}^{1,2,3}$
}

Abstract

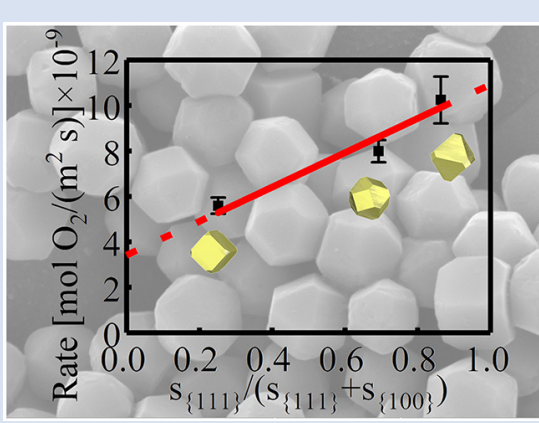

The rapid oxidation of framboidal pyrite is conventionally attributed to its fine grain size. However, the effect of the crystal facets of the microcrystals in the framboids on the oxidation process has been overlooked. We synthesised pyrite monocrystals of microscopic size with both $\{100\}$ and $\{111\}$ facets, which are two major forms of framboidal pyrite crystals, in order to examine the oxidation behaviour of pyrite framboids. The results showed that the oxidation rate of microcrystals with a greater proportion of $\{111\}$ facets was approximately 2 times higher than that of those with a greater proportion of $\{100\}$ facets although the latter's size was smaller. Such a difference makes framboidal pyrite with $\{111\}$ facets more sensitive to oxidative weathering in geochemical cycles than other forms of pyrite. These findings emphasise the role of crystal anisotropy in controlling the oxidation of framboidal pyrite, thereby suggesting that the shape controlled oxidation of pyrite is a potential indicator of the local redox conditions of the palaeoenvironment where it occurred.

Received 10 June 2020 | Accepted 2 January 2021 | Published 9 February 2021

\section{Introduction}

Sedimentary sulfides account for more than $95 \%$ of the sulfides on the surface of the Earth and mainly occur as pyrite in sediments (Rickard et al., 2017). The formation and oxidative weathering of sedimentary pyrite are core processes in the sulfur cycle and are simultaneously involved in other major element cycles (such as carbon, nitrogen, and oxygen) (Hayakawa et al., 2013; Fike et al., 2015; Fakhraee et al., 2019). Thus, these processes have regulated the redox conditions of the Earth's surface through geological history, especially oceanic redox conditions (Wang et al., 2018). Changes in redox conditions also affect the distribution of elements (Anbar, 2008).

Framboidal pyrite, which is the main component and dominant pyrite texture of sedimentary pyrite (Wilkin et al., 1996; Sawlowicz, 2000; Rickard, 2012), plays a major role in the oxidation of sedimentary pyrite. Billions of pyrite grains are forming in sediments and waterways worldwide every second (Ohfuji and Rickard, 2005; Rickard, 2015, 2019a,b). The oldest framboidal pyrite may be found in the late Archean ( $\leq 2.9$ Ga) sediments. (Hallbauer, 1986; Guy et al., 2010).

Pyrite is easily oxidised when exposed to the Earth's oxygenic atmosphere and oceans. The pyrite oxidation process has been investigated extensively for decades, particularly the reaction kinetics and oxidation mechanism. Most previous studies mainly focused on powder samples, i.e. fracture surfaces, and ignored crystal facet effects (Zhu et al., 2018), which may have hindered the accurate determination of the pyrite oxidation mechanism. Moreover, little attention has been paid to the oxidative behaviour of framboidal pyrite, despite its importance in sediments. The oxidation of framboidal pyrite is considered to be fast due to its high specific surface area (SSA) (Pugh et al., 1984; Weber et al., 2004), and the influence of the crystal shape is often neglected. Several studies have shown that framboidal pyrite grains are mostly euhedral microcrystals with specific shapes (mainly with $\{100\}$ and $\{111\}$ facets) (Ohfuji and Rickard, 2005; Rigby et al., 2006; Kozina et al., 2018). Poorly understood issues regarding the rapid oxidation of framboidal pyrite are what controls the oxidation processes; the unique crystal shape or the extremely fine crystal size?

Here, we investigated the surface oxidation behaviour of synthesised sub-micron pyrite with predominantly $\{100\}$ or $\{111\}$ facets. Our results showed that the specific crystal facet of the microscopic pyrite monocrystals, rather than the grain size, dominated its oxidation. Also, the shape controlled oxidation processes of pyrite as indicators of the local redox conditions of the palaeoenvironment are discussed.

\section{Materials and Methods}

Highly pure, specifically shaped microscopic pyrite samples were synthesised using a polymer assisted hydrothermal method, see Supplementary Information (SI). To induce oxidation reactions, the prepared pyrite films were exposed to humidity controlled air

1. CAS Key Laboratory of Mineralogy and Metallogeny/Guangdong Provincial Key Laboratory of Mineral Physics and Materials, Guangzhou Institute of Geochemistry, Chinese Academy of Sciences (CAS), Guangzhou 510640, China

2. CAS Center for Excellence in Deep Earth Science, Guangzhou 510640, China

3. University of Chinese Academy of Sciences, Beijing 100049, China

* Corresponding author (email: xianhaiyang@gig.ac.cn) 
in airtight cells for $84 \mathrm{hr}$ in total. During the oxidation process, the samples were removed for $\mathrm{X}$-ray photoelectron spectroscopy (XPS) analysis at reaction intervals of $0,6,12,24,36,60$, and $84 \mathrm{hr}$. Details of the experimental procedures and characterisation methods are presented in the SI.

\section{Results and Discussion}

Structural, chemical and morphological analyses. No impurity reflections in the X-ray diffraction (XRD) patterns were identified, thereby confirming the high purity of the pyrite samples (Fig. 1a-c). In sample Py-tc (truncated cubic pyrite), the
(111) reflection was relatively weak while the (200) reflection was relatively strong. Compared with those of sample Py-tc, the (111) reflections of samples Py-co (cubo-octahedral pyrite) and Py-to (truncated octahedral pyrite) were stronger, whereas the reflection of (200) was weaker.

Figure $1 \mathrm{~d}-\mathrm{f}$ presents the morphology of the three samples. The change in their morphology indicated that they possessed different proportions of cubic $\{100\}$ and octahedral $\{111\}$ facets, which was identical to the aforementioned XRD results. The energy dispersive spectrometry (EDS) results for all three samples, shown in Figure 1g-i, confirmed the chemical purity of the pyrite phases. It should be noted that there are weak (a)

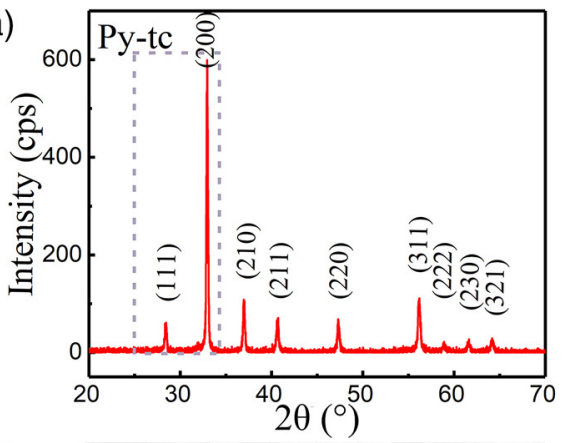

(d)
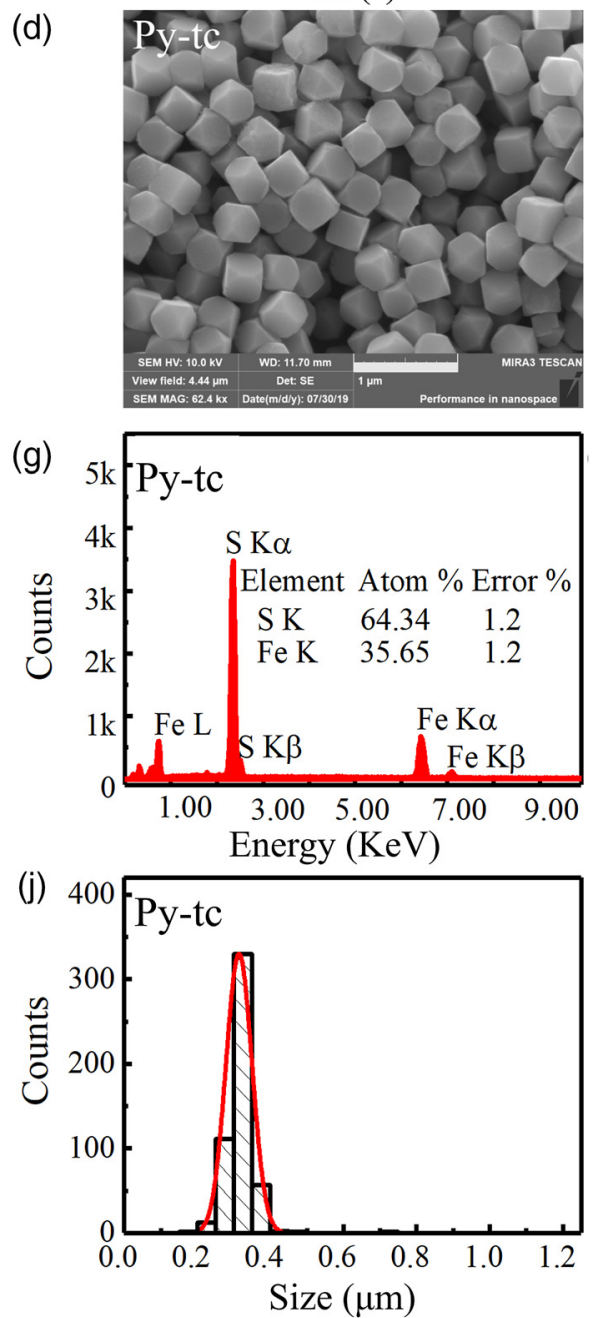

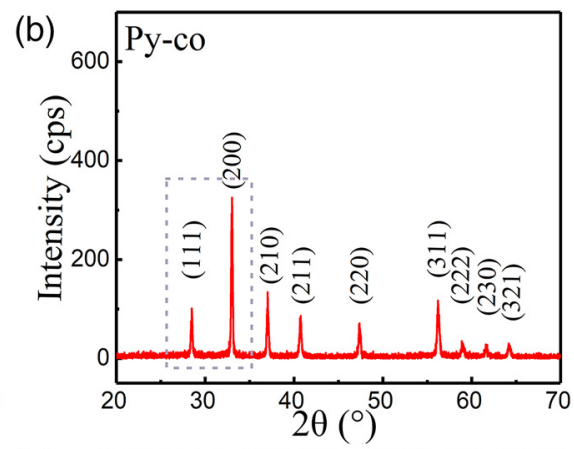

(e)
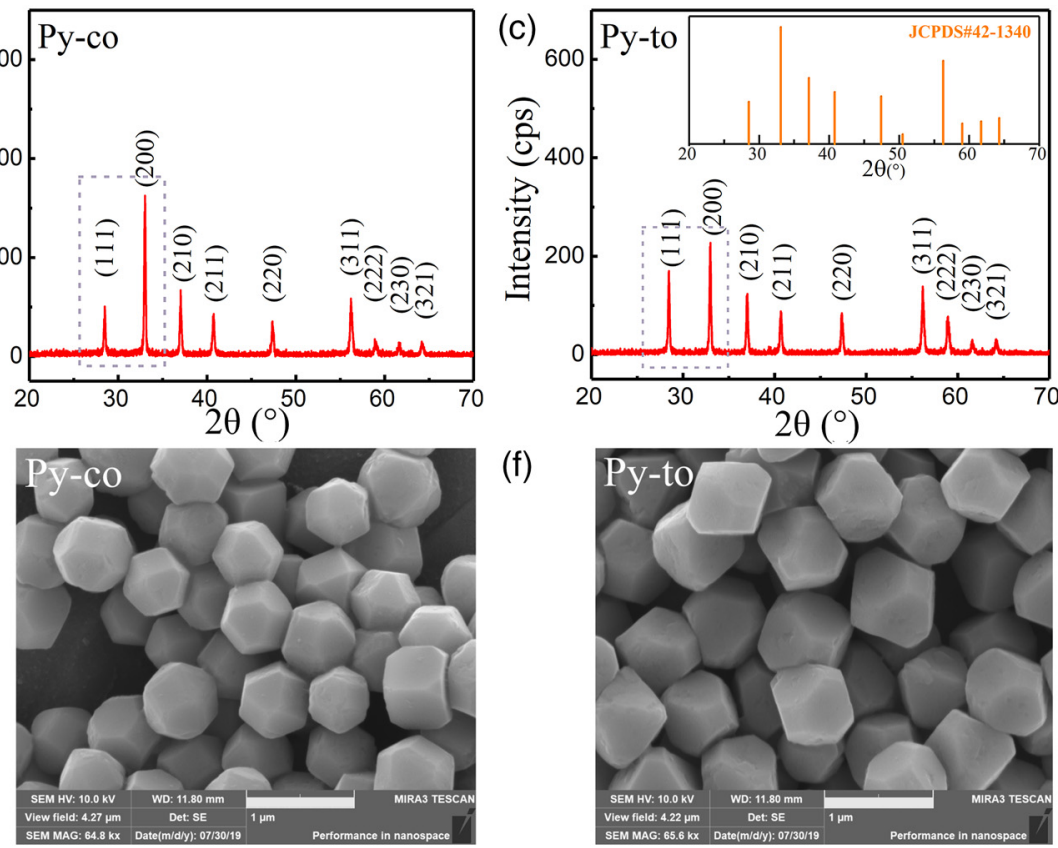

(f)
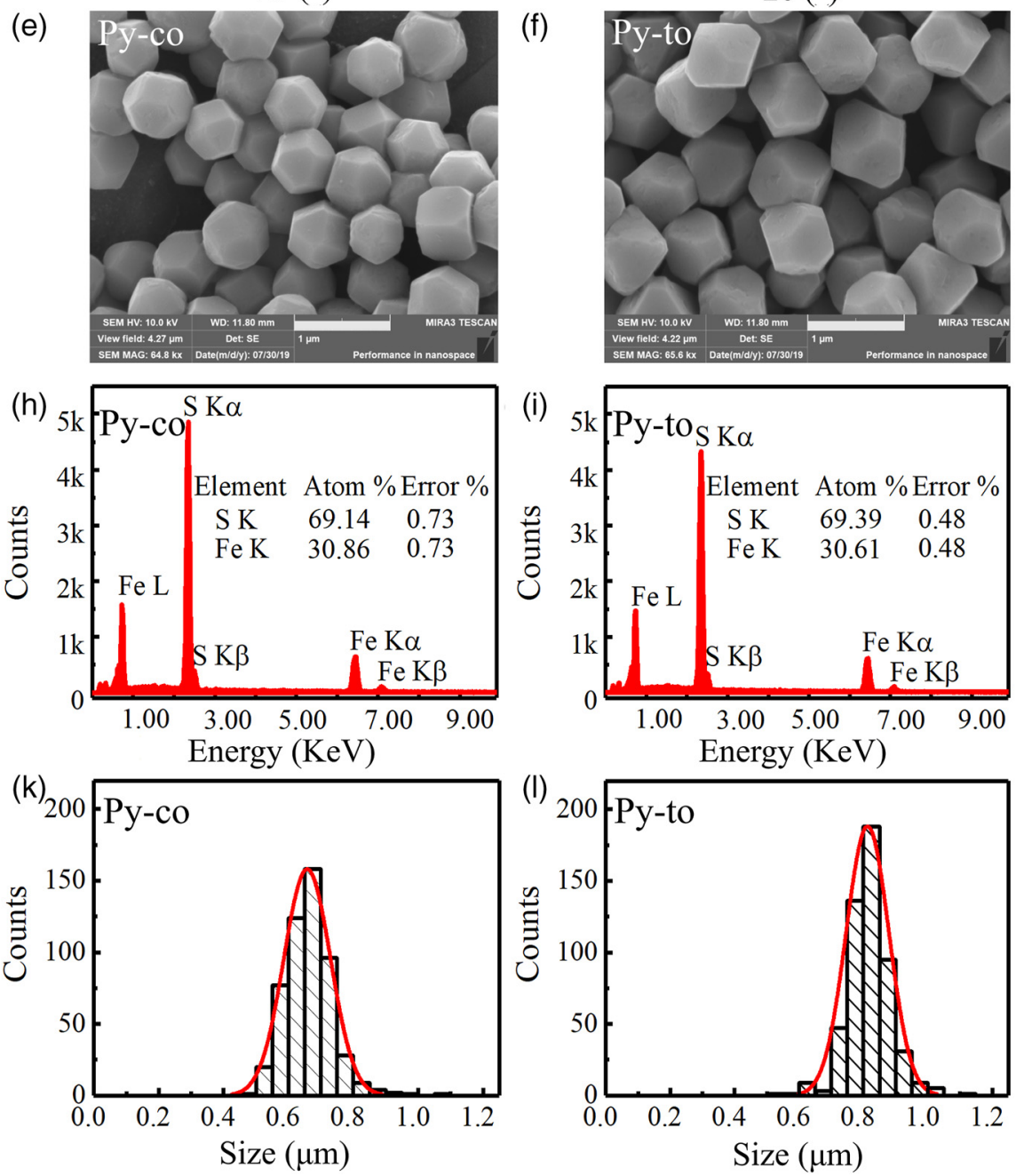

Figure 1 (a-c) X-ray diffraction patterns of synthesised microscopic pyrite samples. (d-f) Field emission scanning electron microscope images of synthesised pyrite samples. (g-i) Energy dispersive spectrometry results of the pyrite samples. The half-quantitative data shown in the spectra were derived from the average measurements of five points. (j-l) Particle size distributions of the pyrite samples, which were derived from the statistical results of at least 500 grains from the micrographs. 
signals in the range of $1-2 \mathrm{KeV}$, which may be due to the introduction of impurities such as $\mathrm{Al}$ and $\mathrm{Si}$ from the environment in the experimental processes, although their concentrations are less than 0.3 wt. \%. EDS results also showed that the Py-co and Py-to samples possessed larger atomic ratios of $\mathrm{S}$ to Fe than the Py-tc sample. This was because the Py-co and Py-to samples possessed larger proportions of $\{111\}$ facets, which are sulfurrich surfaces (Alfonso, 2010), than the Py-tc sample.

Statistical analysis based on field emission scanning electron microscope (FESEM) micrographs showed that the average grain sizes of the Py-tc, $\mathrm{Py}-\mathrm{co}$, and Py-to samples were 305.0, 641.5 and $801.4 \mathrm{~nm}$, respectively (Fig. 1j-1). According to
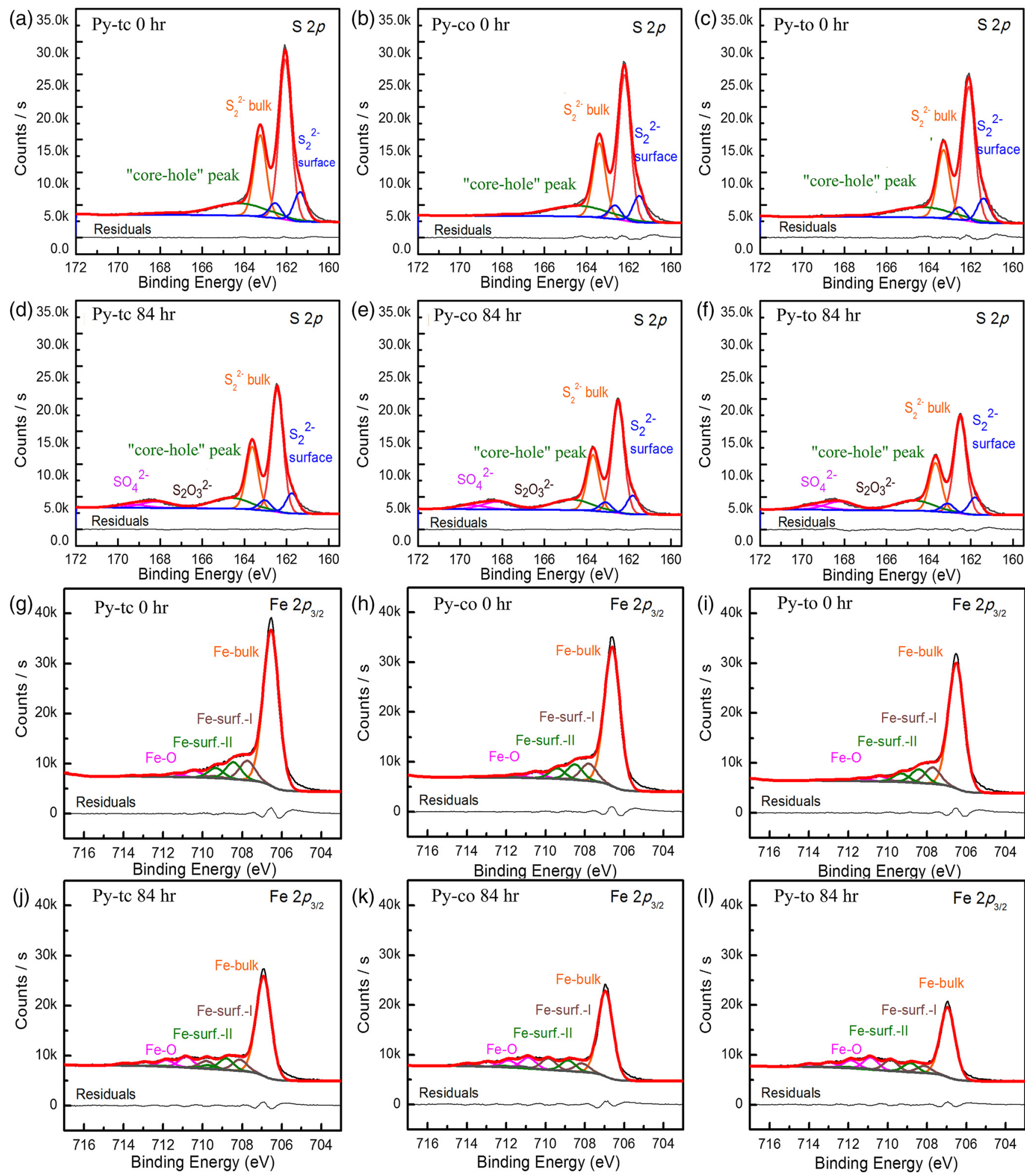

Figure 2 S $2 p(a-f)$ and Fe $2 p_{3 / 2}$ (g-l) X-ray photoelectron spectroscopy spectra of Py-tc (truncated cubic pyrite), Py-co (cubo-octahedral pyrite), and Py-to (truncated octahedral pyrite) surfaces oxidised in air with a relative humidity of $77 \%$ at intervals of $0 \mathrm{hr}$ and $84 \mathrm{hr}$. The Fe-surf.-I and Fe-surf.-Il denote quadruplet and triplet surface states of iron on pyrite, respectively. 
the geometric model (see SI), the SSAs were 2.54, 1.96 and $1.83 \mathrm{~m}^{2} / \mathrm{g}$ for the Py-tc, Py-co and Py-to samples, respectively.

Oxidation rate of microscopic pyrite with different morphologies. Figure 2 shows the S $2 p$ and Fe $2 p_{3 / 2}$ XPS spectra of pyrite before and after oxidation. Here, we used the relative content ratio of oxygen-containing and unoxidised species from the XPS spectra to characterise semi-quantitatively the oxidation rate of the microscopic pyrite (Zhu et al., 2018). The oxygencontaining species from the S $2 p$ XPS spectra included sulfate $\left(\mathrm{SO}_{4}^{2-}\right)$, and the unoxidised species include bulk sulfur $\left(\mathrm{S}_{2}^{2-}\right.$-bulk) and surface sulfur $\left(\mathrm{S}_{2}^{2-}\right.$-surface $)$. The oxygencontaining species from the Fe $2 p$ XPS spectra are iron oxides (Fe-O), and the unoxidised species included bulk iron (Fe-bulk) and surface iron (Fe-surf.-I and Fe-surf.-II). The fitting details of $\mathrm{S} 2 p$ and $\mathrm{Fe} 2 p_{3 / 2}$ XPS spectra are given in the SI.

In addition, the XPS fitting results (Table S-1) showed that thiosulfate was only present at the initial stage of pyrite oxidation, thereby indicating that thiosulfate rapidly converts to sulfate. It is possible that some of these intermediates can be stabilised by impurities in natural pyrites, and thus modify oxidation rates in natural systems. The $\mathrm{S} / \mathrm{Fe}$ ratio at different oxidation intervals (Table S-2) showed an increasing trend over oxidation time. Because the typical altered product of pyrite is an Fe-sulfate, the $\mathrm{S} / \mathrm{Fe}$ ratio should be the same. Changes in this ratio may have been caused by concentration or structural changes, or even changes in the newly formed solid phases.

Figure $3 a, b$ shows the kinetic results of the relative content ratios of oxygen-containing species to unoxidised species. The kinetic data from the S $2 p$ and Fe $2 p_{3 / 2}$ XPS spectra showed the order of the slope $(k)$ for the three samples, i.e. $k_{\text {Py-to }}>$ $k_{\text {Py-co }}>k_{\text {Py-tc }}$. Because $k$ is proportional to the oxidation rate of pyrite (Zhu et al., 2018), the oxidation rates of the three pyrite samples were in the order $r_{\text {Py-to }}>r_{\text {Py-co }}>r_{\text {Py-tc }}$ (Table S-3). The normalised data (Fig. S-3) also showed the same rate order for the three samples.

The order of the oxidation rate was opposite to that of the SSA [i.e. SSA $(\mathrm{Py}-\mathrm{tc})>\mathrm{SSA}(\mathrm{Py}-\mathrm{Co})>\mathrm{SSA}(\mathrm{Py}-\mathrm{to})$ ] for the three samples, thereby suggesting that the crystal morphology (i.e. surface structure), rather than their fine graininduced large SSA, controls the reactivity. Therefore, the crystal morphology should be considered in the oxidation process of framboidal pyrite. The estimated oxidation rates of the samples were proportional to the ratio of microscopic pyrite $\{111\}$ facets to $\{100\}$ facets (Fig. 3c). Therefore, the oxidation rate of microscopic pyrite $\{111\}$ facets is greater than that of $\{100\}$ facets, which is caused by the difference in surface properties between the $\{100\}$ and $\{111\}$ facets (Zhu et al., 2018; Xian et al., 2019). Regardless of grain size, the exposed crystal facet controls the reactivity of the framboidal pyrite microcrystals.

Implications for indicating the local redox conditions of palaeoenvironments. The redox conditions of ancient sediments control the enrichment of biological and redox sensitive trace elements. Pyrite morphology and the size distribution of the framboids are used to indicate palaeoredox conditions (Wilkin and Barnes, 1997a; Wignall et al., 2005; Huang et al., 2016; Liu et al., 2019). Such methods are applicable where there is no oxidative weathering. However, oxidative weathering is always present in ancient sediments. The oxidative products of pyrite, such as magnetite, hematite, limonite, magnesite and goethite, may be the result of pseudomorphism of pyrite (Luther et al., 1982; Wilkin and Barnes, 1997b). Incompletely oxidised pyrite will have a core-shell structure (CourtinNomade et al., 2010; Gu et al., 2020). Based on the results of this study, we propose that such a core-shell structure could indicate the relative redox conditions of the palaeoenvironment. This could be a potential proxy for interpreting local redox conditions, such as local oxidation before the Great Oxidation Event (Anbar et al., 2007).

According to the relationship between the shape of the microcrystalline particles and the oxidation rate (Fig. 3c), different crystal facets of oxidised pyrites may form oxidation species with different thicknesses (Fig. 4a). The relative redox conditions of palaeoenvironments where pyrites were present could therefore be characterised by a redox index $p$, as follows:

$p_{\{h k l\}}=d_{\{h k l\}} / r_{\{h k l\}}$

where $r_{\{h k l\}}$ is the oxidation rate of a specific pyrite facet $\{h k l\}$ (obtained from Fig. 3c), i.e. $r_{\{100\}}=3.63 \times 10^{-9}\left[\mathrm{~mol} \mathrm{O}_{2} / \mathrm{m}^{2} \mathrm{~s}\right]$ and $r_{\{111\}}=10.79 \times 10^{-9}\left[\mathrm{~mol} \mathrm{O}_{2} / \mathrm{m}^{2} \mathrm{~s}\right], d_{\{h k l\}}$ is the thickness of the oxidation shell along the $[\mathrm{hkl}]$ direction. It is worth noting that $p$ is a facet-dependent variable. Without consideration of morphology, one may obtain false signals because of the intrinsic oxidation difference between pyrite facets. In practice, a smaller $p_{\{h k l\}}$ value indicates that the degree of pyrite oxidation is relatively weak, whereas a larger $p_{\{h k l\}}$ value denotes a stronger oxidation.

Figure $4 b, c$ showed core-shell structures of two pyrites from a phosphorus deposit. The $p$ and $p^{\prime}$ are employed to represent the redox indexes of the two pyrites. The estimated redox (a)

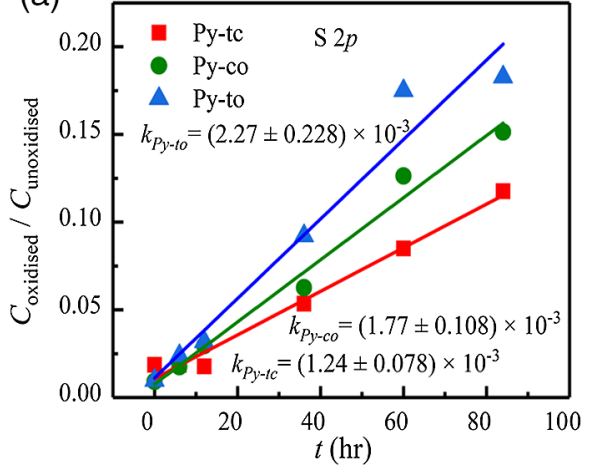

(b)

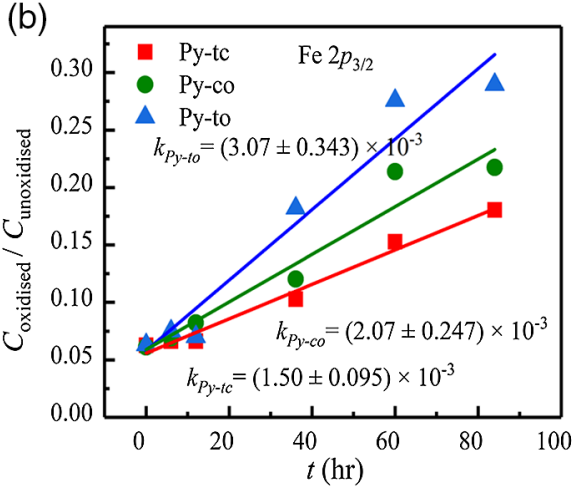

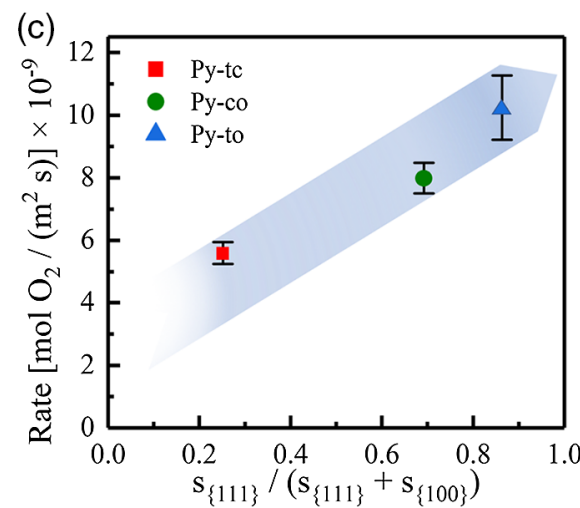

Figure 3 Plots of the concentration ratios of oxidised species to unoxidised species ( $C_{\text {oxidised }} C_{\text {unoxidised }}$ ) vs. oxidation time ( $t$ ) from (a) $S 2 p$ and (b) Fe $2 p_{3 / 2}$. X-ray photoelectron spectroscopy spectra are of Py-tc (truncated cubic pyrite), Py-co (cubo-octahedral pyrite), and Py-to (truncated octahedral pyrite). (c) The estimated oxidation rates of the samples are proportional to the ratio of microscopic pyrite $\{111\}$ facets to $\{100\}$ facets. 

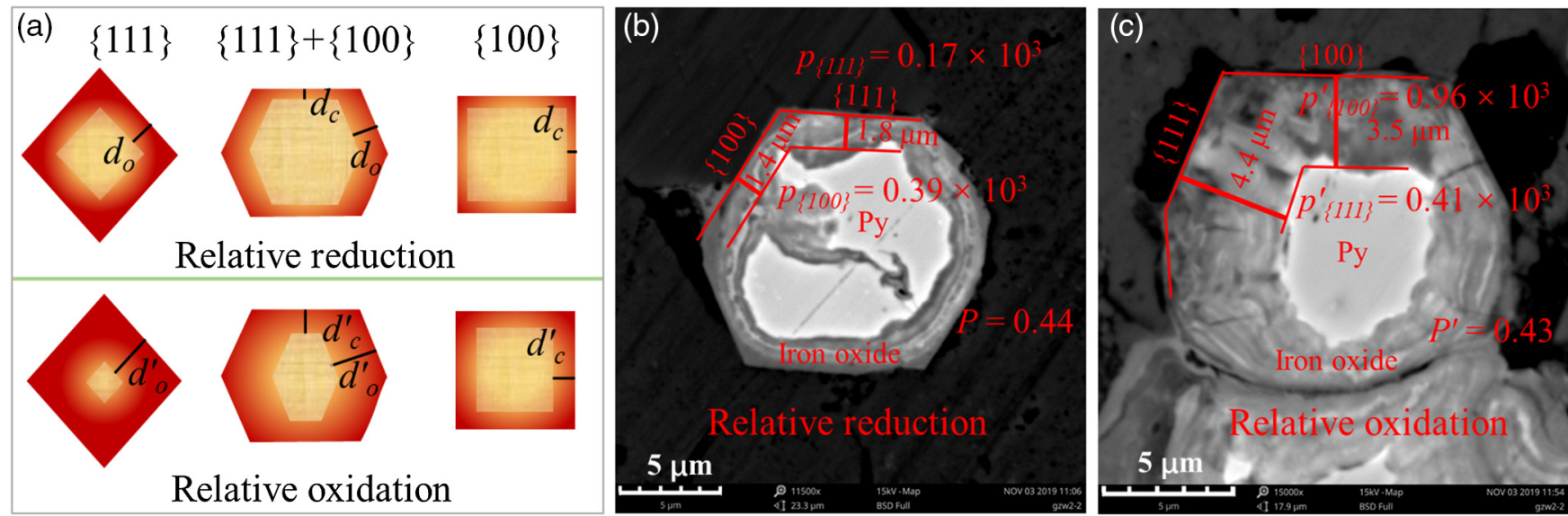

Figure 4 (a) Core-shell models of pyrite with different facets under two redox conditions. The red zone is the oxidised shell and the yellow zone is the unoxidised pyrite core. $(\mathbf{b}, \mathbf{c})$ Core-shell morphologies of oxidised natural pyrites from the Zhijin phosphorus deposit in Guizhou Province, China.

indexes are in the order of $p_{\{111\}}<p^{\prime}{ }_{\{111\}}$, indicating that the latter experienced a more oxidising environment or longer duration of oxidation. Based on the aforementioned definition of the redox index, the $p$ value of all $[h k l]$ directions should be the same, e.g., $p_{\{100\}}=p_{\{111\}}$. However, the calculated $p$ values show that $p_{\{100\}} \neq p_{\{111\}}$ and $p_{\{100\}}^{\prime} \neq p^{\prime}{ }_{\{111\}}$, which may be caused by the diffusion controlled reaction with the increase in the thickness of oxidation layers. Meanwhile, we introduce another index $P$ $\left(P=p_{\{111\}} / p_{\{100\}} \leq 1\right)$. In the initial stage of pyrite oxidation, the reaction is fully controlled by surface structure, which gives $P=1$. With the thickness increase of oxidation products, the reaction is diffusion controlled (the $p_{\{111\}}$ decreases first), resulting in $P<1$. In addition, because $d_{\{100\}}<d_{\{111\}}$, there is a minimum for $P$, i.e. $1>P>r_{\{100\}} / r_{\{111\}}=0.34$. Therefore, higher $P$ (closer to 1) represent a shorter oxidation duration or lower oxygen fugacity, and thus weaker pyrite oxidation. The index $P$ also works well for the pyrites shown in Figure $4 b, c$. Moreover, the presence of impurity elements tends to accelerate the oxidation of natural pyrite (Lehner and Savage, 2008), but it will not affect the assessment of local redox conditions of palaeoenvironments if the presence of impurity elements has the same effect on the oxidation of a pyrite crystal in all crystallographic directions.

\section{Acknowledgements}

This research was funded by the National Natural Science Foundation of China (Grant No.41825003 and 41921003), Natural Science Foundation of Guangdong Province, China (Grant No. 2019A1515011303), China Postdoctoral Science Foundation (Grant Nos. 2018M643220 and 2019T120755), Guangdong Special Support Program (Grant No. 2019TX05L169), Tuguangchi Award for Excellent Young Scholar GIG, CAS, the Science and Technology Planning Project of Guangdong Province, China (Grant No. 2020B1212060055). This is contribution No. IS-2971 from GIG-CAS.

Editor: Satish Myneni

\section{Additional Information}

Supplementary Information accompanies this letter at https:// www.geochemicalperspectivesletters.org/article2104.

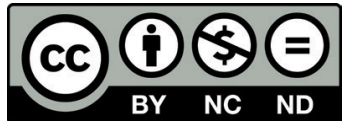

(C) 2021 The Authors. This work is distributed under the Creative Commons Attribution NonCommercial No-Derivatives 4.0 License, which permits unrestricted distribution provided the original author and source are credited. The material may not be adapted (remixed, transformed or built upon) or used for commercial purposes without written permission from the author. Additional information is available at https://www. geochemicalperspectivesletters.org/copyright-and-permissions.

Cite this letter as: Du, R., Xian, H., Wu, X., Zhu, J., Wei, J., Xing, J., Tan, W., He, H. (2021) Morphology dominated rapid oxidation of framboidal pyrite. Geochem. Persp. Let. 16, 53-58.

\section{References}

Alfonso, D.R. (2010) Computational Investigation of $\mathrm{FeS}_{2}$ Surfaces and Prediction of Effects of Sulfur Environment on Stabilities. Journal of Physical Chemistry C 114, 8971-8980.

ANBAR, A.D. (2008) Elements and Evolution. Science 322, 1481-1483.

Anbar, A.D., Duan, Y., Lyons, T.W., Arnold, G.L., Kendall, B., Creaser, R.A., Kaufman, A.J., Gordon, G.W., Scott, C., Garvin, J., Buick, R. (2007) A Whiff of Oxygen Before the Great Oxidation Event? Science 317, 1903-1906.

Courtin-Nomade, A., Bril, H., BénY, J.-M., Kunz, M., Tamura, N. (2010) Sulfide oxidation observed using micro-Raman spectroscopy and micro-X-ray diffraction: The importance of water/rock ratios and $\mathrm{pH}$ conditions. American Mineralogist 95, 582-591.

Fakhraee, M., Hancisse, O., Canfield, D.E., Crowe, S.A., Katsev, S. (2019) Proterozoic seawater sulfate scarcity and the evolution of oceanatmosphere chemistry. Nature Geoscience 12, 375-380.

Fike, D.A., Bradley, A.S., Rose, C.V. (2015) Rethinking the Ancient Sulfur Cycle. Annual Review of Earth and Planetary Sciences 43, 593-622.

Gu, X., Heaney, P.J., Reis, F.D.A.A., Brantley, S.L. (2020) Deep abiotic weathering of pyrite. Science 370, doi: 10.1126/science.abb8092.

GuY, B.M., BeuKes, N.J., GutZmer, J. (2010) Paleoenvironmental controls on the texture and chemical composition of pyrite from non-conglomeratic sedimentary rocks of the Mesoarchean Witwatersrand Supergroup, South Africa. South African Journal of Geology 113, 195-228.

Hallbaufr, D.K. (1986) The mineralogy and geochemistry of Witwatersrand pyrite gold, uranium and carbonaceous matter mineral deposits of South Africa. In: Anhauesser, C.R., Maske, S. (Eds.) Mineral Deposits of Southern Africa. Geological Society of South Africa, South Africa, Vol. 1, 731-752.

Hayakawa, A., Hatakeyama, M., Asano, R., Ishikawa, Y., Hidaka, S. (2013) Nitrate reduction coupled with pyrite oxidation in the surface sediments of a 
sulfide-rich ecosystem. Journal of Geophysical Research: Biogeosciences 118, 639-649.

Hunang, Y., Chen, Z.-Q., Wignall, P.B., Zhao, L. (2016) Latest Permian to Middle Triassic redox condition variations in ramp settings, South China: Pyrite framboid evidence. Geological Society of America Bulletin 129, 15.

Kozina, N., ReYKHARD, L., Dara, O., GordeEv, V. (2018) Framboidal pyrite formation in the bottom sediments of the South Caspian Basin under conditions of hydrogen sulfide contamination. Russian Journal of Earth Sciences 18, 1-10.

LeHner, S., SAVAge, K. (2008) The effect of As, Co, and Ni impurities on pyrite oxidation kinetics: Batch and flow-through reactor experiments with synthetic pyrite. Geochimica et Cosmochimica Acta 72, 1788-1800.

Liu, Z., Chen, D., Zhang, J., LÜ, X., WANG, Z., LiaO, W., ShI, X., TANG, J., XIE, G. (2019) Pyrite Morphology as an Indicator of Paleoredox Conditions and Shale Ga Content of the Longmaxi and Wufeng Shales in the Middle Yangtze Area, South China. Minerals 9, 428

Luther, G.W., Giblin, A., Howarth, R.W., RYans, R.A. (1982) Pyrite and Oxidized Iron Mineral Phases Formed from Pyrite Oxidation in Salt-Marsh and Estuarine Sediments. Geochimica et Cosmochimica Acta 46, 2665-2669.

OHFujI, H., RicKARD, D. (2005) Experimental syntheses of framboids-a review. Earth-Science Reviews 71, 147-170.

Pugh, C.E., Hossner, L.R., Dixon, J.B. (1984) Oxidation rate of iron sulfides as affected by surface area, morphology, oxygen concentration and autotrophic bacteria. Soil Science 137, 309-314.

RicKARD, D. (2012) Sulfidic Sediments and Sedimentary Rocks. Elsevier, Amsterdam, Netherlands.

RicKARD, D. (2015) Pyrite: A Natural History of Fool's Gold. Oxford University Press, New York.

RICKARD, D. (2019a) How long does it take a pyrite framboid to form? Earth and Planetary Science Letters 513, 64-68.

RICKARD, D. (2019b) Sedimentary pyrite framboid size-frequency distributions: A meta-analysis. Palaeogeography, Palaeoclimatology, Palaeoecology 522, $62-75$.

Rickard, D., Mussmann, M., Steadman, J.A. (2017) Sedimentary Sulfides. Elements 13, 117-122.

Rigby, P.A., Dobos, S.K., Cook, F.J., Goonetilleke, A. (2006) Role of organic matter in framboidal pyrite oxidation. Science of The Total Environment $367,847-854$.

SAwlowicz, Z. (2000) Framboids: From their origin to application. Prace Mineralogiczne, Kraków, Poland.

Wang, P., Tian, J., Huang, E. (2018) Earth system and evolution. Science Press, Beijing.

Weber, P.A., Stewart, W.A., Skinner, W.M., Weisener, C.G., Thomas, J.E. SMART, R.ST.C. (2004) Geochemical effects of oxidation products and framboidal pyrite oxidation in acid mine drainage prediction techniques. Applied Geochemistry 19, 1953-1974.

Wignall, P.B., Newton, R., Brookfield, M.E. (2005) Pyrite framboid evidence for oxygen-poor deposition during the Permian-Triassic crisis in Kashmir. Palaeogeography, Palaeoclimatology, Palaeoecology 216, 183-188.

Wilkin, R.T., Barnes, H.L. (1997a) Pyrite formation in an anoxic estuarine basin American Journal of Science 297, 620-650.

WilKIN, R.T., BarNeS, H.L. (1997b) Formation processes of framboidal pyrite Geochimica et Cosmochimica Acta 61, 323-339.

WILKIN, R.T, BarNES, H.L, BRANTLEY, S.L. (1996) The size distribution of framboida pyrite in modern sediments: An indicator of redox conditions. Geochimica et Cosmochimica Acta 60, 3897-3912.

Xian, H., He, H., Zhu, J., Du, R., Wu, X., Tang, H., Tan, W., Liang, X., Zhu, R., TENG, H. (2019) Crystal habit-directed gold deposition on pyrite: Surface chemical interpretation of the pyrite morphology indicative of gold enrichment. Geochimica et Cosmochimica Acta 264, 191-204.

Zhu, J., XiAn, H., Lin, X., TANG, H., Du, R., Yang, Y., Zhu, R., Liang, X., Wei, J., TENG, H., HE, H. (2018) Surface structure-dependent pyrite oxidation in relatively dry and moist air: Implications for the reaction mechanism and sulfur evolution. Geochimica et Cosmochimica Acta 228, 259-274. 